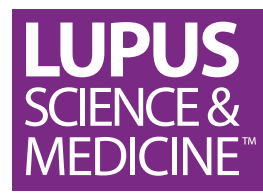

\title{
Outcome of participants with nephrotic syndrome in combined clinical trials of lupus nephritis
}

To cite: Gomez Mendez LM, Cascino MD, Katsumoto TR, et al. Outcome of participants with nephrotic syndrome in combined clinical trials of lupus nephritis. Lupus Science \& Medicine 2019;6:e000308. doi:10.1136/ lupus-2018-000308

Received 29 0ctober 2018 Revised 31 December 2018 Accepted 6 January 2019

Check for updates

(c) Author(s) (or their employer(s)) 2019. Re-use permitted under CC BY-NC. No commercial re-use. See rights and permissions. Published by BMJ.

${ }^{1}$ Department of Pediatric Nephrology, University of California San Francisco, San Francisco, California, USA ${ }^{2}$ Product Development Clinical Science, Genentech Inc, South San Francisco, California, USA

${ }^{3}$ Early Development, Genentech Inc, South San Francisco, CA, United States

${ }^{4}$ Department of Medicine, University of Cambridge School of Clinical Medicine, Cambridge, UK

${ }^{5}$ Department of Rheumatology, University of California San Francisco, San Francisco , CA, United States

${ }^{6}$ Department of Internal Medicine/Nephrology, Ohio State University Wexner Medical Center, Columbus, Ohio, USA

Correspondence to Dr Liliana Michelle Gomez Mendez; michelle2108@gmail. com

\section{ABSTRACT}

Objective The outcome of participants with nephrotic syndrome in clinical trials of lupus nephritis has not been studied in detail.

Methods Collated data from two randomised controlled trials in lupus nephritis, Lupus Nephritis Assessment of Rituximab (LUNAR) and A Study to Evaluate Ocrelizumab in Patients With Nephritis due to Systemic Lupus Erythematosus (BELONG) were analysed. Nephrotic syndrome was defined as albumin $<3 \mathrm{~g} / \mathrm{dL}$ and urine protein/creatinine ratio $\geq 3.5 \mathrm{~g} / \mathrm{g}$ at start of trial. Renal response was defined as a first morning urine protein/ creatinine ratio $\leq 0.5 \mathrm{~g} / \mathrm{g}$ in addition to $\leq 25 \%$ increase in creatinine from trial entry assessed at week 48 . Logistic regression was used to evaluate the association of nephrotic syndrome with renal response while adjusting for treatment received and ACE inhibitor or angiotensin receptor blocker use.

Results $28(26 \%)$ participants with nephrotic syndrome achieved renal response as compared with 130 (52.5\%) of those without $(p<0.001)$. Having nephrotic syndrome at baseline significantly lowered the likelihood of achieving renal response (OR 0.32, $95 \% \mathrm{Cl} 0.19$ to $0.54, \mathrm{p}<0.001$ ). $125(80 \%)$ participants achieved resolution of their nephrotic syndrome in a median time of 16 weeks. Conclusions Nephrotic syndrome at baseline decreases the likelihood of renal response at 1 year. Longer clinical trials or better short-term predictors of long-term outcomes may better assess the effect of novel therapeutic approaches on subjects with nephrotic syndrome.

\section{INTRODUCTION}

Nephrotic syndrome is a common manifestation of glomerular disease. Characterised by a high degree of proteinuria, low serum albumin, hyperlipidaemia and oedema, ${ }^{1}$ it is the cause of serious complications including infections, hypertension and hypercoagulability. $^{2-4}$ The reported percentage of subjects with lupus nephritis who present with nephrotic syndrome ranges from $30 \%$ to $70 \% .^{5-15}$ Nephrotic syndrome has important prognostic implications for lupus nephritis. In two longitudinal cohorts, subjects with nephrotic syndrome at cohort inception had a significantly lower likelihood of renal survival at 25 years. ${ }^{78}$ In spite of its prognostic implications, only two large clinical trials have reported their prevalence of nephrotic syndrome at trial entry: Euro-Lupus Nephritis Trial (ELNT) with $28 \%^{16}$ and Tacrolimus versus Mycophenolate Mofetil for Induction Therapy of Lupus Nephritis trial with $43 \% .^{13}$

Nephrotic syndrome can be present in lupus nephritis classes II-V. ${ }^{77-20}$ On biopsy, it is associated with podocyte effacement, and a greater degree of effacement correlates with a higher amount of proteinuria. ${ }^{19-23}$ Immune complex deposition in the glomerular subendothelial or subepithelial space has been considered the source of podocyte damage resulting in effacement. ${ }^{24}$ However, podocyte effacement can be present in the absence of immune complex deposition, an entity termed 'lupus podocytopathy',23 which suggests that alternative mechanisms of podocyte injury exist. $^{22} 25$ Podocyte effacement is not included in the International Society of Nephrology (ISN)/Renal Pathology Society (RPS)ISN/ RPS lupus nephritis classification. ${ }^{26}$

Prospective cohorts have shown that subjects with lupus nephritis and elevated baseline proteinuria (greater than $2-3.5 \mathrm{~g}$ /day) have a lower probability of achieving renal response within a year. Nonetheless, many achieve renal response after 1 year. ${ }^{1728} 28$ Subjects with elevated proteinuria, such as those with nephrotic syndrome, may require more time to reach a specific urine protein threshold; therefore, longer trials may better assess the effect of novel therapeutic approaches in this subgroup. Additionally, reductions in proteinuria of $>50 \%$ in the first 6 months of treatment have also been associated with good long-term outcomes in lupus nephritis ${ }^{1629}$ and may be a better long-term prognostic indicator than 1 year proteinuria levels in those with baseline 
nephrotic syndrome, although this has not been validated in prospective cohorts.

No major lupus nephritis trial has analysed the outcomes of subjects with nephrotic syndrome as a distinct subgroup. We sought to evaluate whether subjects with nephrotic syndrome at baseline had a lower likelihood of achieving renal response over 48 weeks of observation as compared with non-nephrotic subjects by using combined data from the Lupus Nephritis Assessment of Rituximab (LUNAR) and A Study to Evaluate Ocrelizumab in Patients With Nephritis due to Systemic Lupus Erythematosus (BELONG); two large randomised controlled trials testing the efficacy of rituximab and ocrelizumab in lupus nephritis. ${ }^{30} 31$

\section{METHODS \\ Participants}

The combined BELONG and LUNAR trials comprised 525 participants. The LUNAR trial (clinicaltrials.gov identifier NCT00282347) ${ }^{30}$ randomised 144 participants to rituximab $(\mathrm{n}=72)$ or placebo $(\mathrm{n}=72)$ from January 2006 to January 2008. The BELONG trial (clinicaltrials. gov identifier NCT00626197) ${ }^{31}$ randomised 381 participants to $1000 \mathrm{mg}$ ocrelizumab ( $\mathrm{n}=128), 400 \mathrm{mg}$ ocrelizumab $(\mathrm{n}=127)$ or placebo $(\mathrm{N}=126)$ from February 2008 to October 2009. For both trials, participants were required to fulfil the American College of Rheumatology criteria for SLE as well as have renal biopsy showing Class $\mathrm{III} \pm \mathrm{V}$ or Class $\mathrm{IV} \pm \mathrm{V}$.

\section{Treatment protocol}

In the LUNAR trial, participants received either placebo or $1 \mathrm{~g}$ of rituximab on days 1, 15, 168 and 182. Mycophenolate mofetil (MMF) was maintained at $3 \mathrm{~g} /$ day. Three grams of methylprednisolone were given by day 3 . Oral steroids starting at $0.75 \mathrm{mg} / \mathrm{kg} /$ day were tapered to 10 $\mathrm{mg} /$ day by week 16 . The primary endpoint was assessed at week 52. In the BELONG trial, participants received placebo, $400 \mathrm{mg}$ ocrelizumab or $1000 \mathrm{mg}$ ocrelizumab on days 1 and 15 , at week 16 and every 16 weeks thereafter. Two hundred and thirty-nine participants (63\%) in BELONG trial were maintained on MMF at $3 \mathrm{~g} /$ day, while 142 participants (37\%) received cyclophosphamide according to the ELNT regimen ${ }^{32}$ followed by azathioprine $2 \mathrm{mg} / \mathrm{kg} /$ day. Three grams of methylprednisolone were given by day 15 . Oral steroids starting at $0.5-0.75$ $\mathrm{mg} / \mathrm{kg} /$ day were tapered to $10 \mathrm{mg} /$ day by week 10 . The primary endpoint was assessed at week 48 . The BELONG trial was terminated early due to a benefit/risk assessment that did not support the continued development of ocrelizumab for lupus nephritis. Importantly, rituximab and ocrelizumab are not approved for use in lupus nephritis.

\section{Clinical considerations}

First visit urine protein/creatinine ratio (UPCR) was obtained from a 24-hour urine collection. For all subsequent visits, UPCRs were obtained from first morning urine spot samples. Nephrotic syndrome was defined as UPCR $\geq 3.5 \mathrm{~g} / \mathrm{g}$ and serum albumin $<3 \mathrm{~g} / \mathrm{dL}$ at start of trial. Resolution of nephrotic syndrome was defined as UPCR $<3.5$ and albumin $\geq 3 \mathrm{~g} / \mathrm{dL}$. The average daily steroid dose and average daily MMF dose were calculated only in participants who completed 48 weeks in the trials $(n=356)$. For the average daily steroid dose, only the steroid taper was considered. Pulse steroids or premedication doses were not used in this calculation. Normal C3 was considered to be $\geq 90 \mathrm{mg} / \mathrm{dL}$ and a negative anti-dsDNA antibody was considered to be $\leq 30 \mathrm{IU} /$ $\mathrm{mL}$. Starting an ACE inhibitor or an angiotensin receptor blocker (ARB) at screening was required in LUNAR trial and recommended in BELONG trial. Continuation of $\mathrm{ACE} / \mathrm{ARB}$ was encouraged in both trials but was left at the discretion of the principal investigator. For these analyses, ACE/ARB use was considered positive if participants received it for a period of at least 3 months.

\section{Endpoints}

BELONG renal response criteria included a UPCR $\leq 0.5$ $\mathrm{g} / \mathrm{g}$ in addition to $\leq 25 \%$ increase in creatinine from trial entry, assessed at week 48 . LUNAR renal response criteria included UPCR $\leq 0.5 \mathrm{~g} / \mathrm{g}$ in addition to $\leq 15 \%$ increase in creatinine from trial entry and inactive urinary sediment ( $<5$ red blood cells (RBC) per high-power field and the absence of RBC casts) assessed at week 52. In order to combine data from both trials, BELONG's definition of renal response was used and assessed at week 48. An additional endpoint explored was time to resolution of nephrotic syndrome in weeks.

\section{Statistical analysis}

Differences in baseline characteristics were assessed by Student's t-test, $\chi^{2}$ test or Mann-Whitney $U$ test as appropriate. Logistic regression was used to assess the relationship between nephrotic syndrome and binary outcomes, and linear regression was used to assess the relationship between nephrotic syndrome and continuous outcomes. Regressions were adjusted for treatment received and ACE/ARB use. Kaplan-Meier survival analyses were used to analyse time to events. HRs were used to compare likelihood of event occurrences. The screening value for UPCR and albumin was imputed for four participants with missing day 1 values. Week 52 values were imputed for 10 participants from the LUNAR trial with missing week 48 values. Analyses were performed using STATA V.14.2 software. A two-sided $p$ value of $<0.05$ was considered statistically significant.

\section{RESULTS}

\section{Analysis of baseline characteristics}

Five hundred and twenty-two subjects had complete baseline information. One hundred and fifty-seven (30\%) subjects had baseline nephrotic syndrome. Subjects with nephrotic syndrome had higher levels of UPCR (6.7 vs $2.2 \mathrm{~g} / \mathrm{g}, \mathrm{p}<0.001$ ), total cholesterol (306 vs $237 \mathrm{mg} / \mathrm{dL}$, $\mathrm{p}<0.001$ ), low-density lipoprotein (191 vs $141 \mathrm{mg} / \mathrm{dL}$, $\mathrm{p}<0.001$ ) and triglycerides (225 vs $161 \mathrm{mg} / \mathrm{dL}, \mathrm{p}<0.001$ ), 
as well as higher diastolic (83 vs $78 \mathrm{~mm} \mathrm{Hg}, \mathrm{p}<0.001$ ) and systolic ( 130 vs $124 \mathrm{~mm} \mathrm{Hg}, \mathrm{p}<0.001$ ) blood pressure. They also had lower estimated glomerular filtration rate (eGFR) (73 vs $91 \mathrm{~mL} / \mathrm{min}, \mathrm{p}<0.001$ ), as well as lower levels of serum albumin ( $2.3 \mathrm{vs} 3.3 \mathrm{~g} / \mathrm{dL}, \mathrm{p}<0.001)$, immunoglobulin $\mathrm{G}(7.9$ vs $10.9 \mathrm{~g} / \mathrm{dL}, \mathrm{p}<0.001)$ and C3 ( 60 vs $65 \mathrm{mg} / \mathrm{dL}, \mathrm{p}=0.02$ ). There was a greater proportion of biopsies with mixed Class III/V and IV/V in those with nephrotic syndrome as compared with those without $(30.5 \%$ vs $19 \%, \mathrm{p}=0.004)$ (table 1$)$.

\section{Achievement of renal response}

Due to the early termination of BELONG trial and other reasons for early withdrawal, $356(68 \%)$ participants had UPCR and creatinine values up to week 48 . Of these, 28 $(26 \%)$ with baseline nephrotic syndrome achieved renal response, as compared with $130(52.5 \%)$ of those without $(\mathrm{p}<0.001)$. Having nephrotic syndrome at baseline associated with a lower likelihood of achieving renal response adjusting for treatment received and ACE/ARB use: OR $0.32,95 \%$ CI 0.19 to $0.54, \mathrm{p}<0.001$. A sensitivity analysis using the original response criteria for each trial showed quantitatively similar results (adjusted OR 0.38, 95\% CI 0.22 to $0.64, \mathrm{p}<0.001)$.

\section{Reduction in proteinuria}

Those with baseline nephrotic syndrome had on average a $2.9 \mathrm{~g} / \mathrm{g}(95 \% \mathrm{CI}-3.4$, to $2.4, \mathrm{p}<0.001)$ greater drop in proteinuria at week 24 and $3.3 \mathrm{~g} / \mathrm{g}(95 \%$ CI -3.9 , to 2.7 , $\mathrm{p}<0.001)$ greater drop in proteinuria at week 48 compared with non-nephrotic subjects (figure 1a). A greater percentage of subjects with nephrotic syndrome achieved $50 \%$ decrease in proteinuria at week $24(71 \%$ vs $61 \%$, $\mathrm{p}=0.04)$ and week $48(80 \%$ vs $70 \%, \mathrm{p}=0.05)$ as compared with non-nephrotic subjects. Evaluating subjects from the LUNAR trial with data up to week 78 , the lowest mean UPCR for subjects with nephrotic syndrome $(n=48)$ was achieved at week $64(1.2 \mathrm{~g} / \mathrm{g})$, whereas for those without nephrotic syndrome $(\mathrm{n}=72)$ it was achieved at week 52 $(0.78 \mathrm{~g} / \mathrm{g})$ (figure $1 \mathrm{~b})$.

\section{Comparison of normalisation of serologies and average daily medication doses}

The HR (adjusted for treatment received) of normalisation of C3 in subjects with nephrotic syndrome was 1.08 relative to non-nephrotic subjects $(95 \%$ CI 0.8 to 1.3, $\mathrm{p}=0.4$ ). The HR (adjusted for treatment received) of anti-dsDNA antibody becoming negative in subjects with nephrotic syndrome was 1.5 relative to non-nephrotic subjects ( $95 \%$ CI 1.18 to $1.96, \mathrm{p}=0.001$ ). Subjects with nephrotic syndrome did not receive a significantly greater average daily steroid dose than non-nephrotic subjects when analysed within individual trials: LUNAR ( 18 vs $18 \mathrm{mg}, \mathrm{p}=0.9$ ) and BELONG (15.5 vs $14 \mathrm{mg}, \mathrm{p}=0.4$ ). Subjects with nephrotic syndrome also did not receive a significantly greater average daily MMF dose (2.5 vs 2.5, $\mathrm{p}=0.9)$.

\section{Resolution of nephrotic syndrome}

One hundred and fifty-seven subjects with nephrotic syndrome at baseline were analysed. One hundred and twenty-five (80\%) subjects achieved resolution of nephrotic syndrome in a median time of 16 weeks (range 4-48, figure 2). Thirty-two subjects were censored prior to resolution of nephrotic syndrome including 13 subjects that were followed up to week 48. Reasons for censoring included early trial withdrawal, early termination of BELONG trial and reaching end of study period (week 48). Time to resolution of nephrotic syndrome by treatment arm was quite varied. The HR (adjusted for ACE/ ARB use) of resolution of nephrotic syndrome in those treated with rituximab+MMF was 0.6 relative to $\mathrm{MMF}+$ placebo (95\% CI 0.34 to $1.0, \mathrm{p}=0.05$ ). The HR (adjusted for $\mathrm{ACE} / \mathrm{ARB}$ use) of resolution of nephrotic syndrome in those treated with any anti-CD20 therapy was 0.79 relative to any placebo therapy (95\% CI 0.55 to $1.14, \mathrm{p}=0.2$ ).

\section{Renal response in subjects with baseline nephrotic syndrome} One hundred and eight subjects (of 157) with baseline nephrotic syndrome had UPCR and creatinine values up to week 48 . Twenty-eight participants (26\%) achieved renal response. Those who achieved response had lower baseline UPCR ( 5.6 vs $6.9, \mathrm{p}=0.02$ ) but baseline albumin was similar (2.3 vs 2.2, $\mathrm{p}=0.1$ ) (table 2). Participants who achieved response also had a trend in greater decrease in proteinuria at week $24(-4.9 \mathrm{vs}-3.8 \mathrm{~g} / \mathrm{g}, \mathrm{p}=0.1)$ and week $48(-5.5 \mathrm{vs}-4.3 \mathrm{~g} / \mathrm{g}, \mathrm{p}=0.1)$ as well as a greater increase in albumin at week 48 (1.6 vs $1.3, \mathrm{p}=0.06)$. Responders had greater decreases in systolic $(-24$ vs $-13 \mathrm{~mm} \mathrm{Hg}, \mathrm{p}=0.02)$ and diastolic ( -13 vs $-6 \mathrm{~mm} \mathrm{Hg}, \mathrm{p}=0.04)$ blood pressure. All subjects that achieved renal response had greater than $50 \%$ reduction in proteinuria at week 24 . When analysed by trial, responders were treated with a similar average daily steroid dose in LUNAR ( 17.5 vs $18.5 \mathrm{mg}, \mathrm{p}=0.8$ ) trial and a lower average daily steroid dose in BELONG (12 vs $16 \mathrm{mg}, \mathrm{p}=0.01$ ) trial (figure 3).

\section{DISCUSSION}

Nephrotic syndrome, as initial disease presentation or as a disease flare, has important prognostic implications for treatment outcomes in lupus nephritis. Using collated data from the LUNAR and BELONG trials, we have shown that subjects with baseline nephrotic syndrome have a lower likelihood of achieving renal response in the course of 48 weeks of observation as compared with those without nephrotic syndrome. Similarly, observational studies ${ }^{1533}$ have found a lower proportion of renal response in participants with nephrotic syndrome at 1 year. Despite the unique challenges that participants with nephrotic syndrome face, no major lupus nephritis trial has analysed the outcomes of these participants as a distinct subgroup. In spite of this difference in outcomes, the majority of participants with nephrotic syndrome in LUNAR and BELONG demonstrated clinically important improvements during their time in the trials. They had 
Table 1 Baseline characteristics comparing subjects from the Lupus Nephritis Assessment of Rituximab and A Study to Evaluate Ocrelizumab in Patients With Nephritis due to Systemic Lupus Erythematosus trials with baseline nephrotic syndrome versus subjects without

\begin{tabular}{|c|c|c|c|}
\hline & $\begin{array}{l}\text { Nephrotic syndrome, } \mathrm{N}=157 \\
(30 \%)\end{array}$ & $\begin{array}{l}\text { Without nephrotic } \\
\text { syndrome, } \mathrm{N}=365 \text { (70\%) }\end{array}$ & $P$ value \\
\hline $\begin{array}{l}\text { Age, years } \\
\text { Mean } \pm S D\end{array}$ & $30.3 \pm 9.2$ & $31.3 \pm 9.6$ & 0.2 \\
\hline Female & $142(90.5 \%)$ & $318(87 \%)$ & 0.3 \\
\hline $\begin{array}{l}\text { Duration of lupus nephritis, months } \\
\text { Median (IQR range) }\end{array}$ & $8.9(1.8-45.8)$ & $8.6(1.9-57)$ & 0.7 \\
\hline ACE or angiotension receptor blocker & 109 (69\%) & 242 (66\%) & 0.5 \\
\hline Thrombotic event & $6(4 \%)$ & $6(1.8 \%)$ & 0.1 \\
\hline $\begin{array}{l}\text { Cholesterol, mg/dL } \\
\text { Mean } \pm \text { SD }\end{array}$ & $306 \pm 102$ & $237 \pm 67$ & $<0.001$ \\
\hline $\begin{array}{l}\text { Low-density lipoprotein, mg/dL } \\
\text { Mean } \pm S D\end{array}$ & $191 \pm 80$ & $141 \pm 55$ & $<0.001$ \\
\hline $\begin{array}{l}\text { High-density lipoprotein, mg/dL } \\
\text { Mean } \pm \text { SD }\end{array}$ & $55 \pm 17$ & $57 \pm 19$ & 0.2 \\
\hline $\begin{array}{l}\text { Triglycerides, mg/dL } \\
\text { Median (IQR range) }\end{array}$ & $225(157-348)$ & $161(115-227)$ & $<0.001$ \\
\hline Treatment received & & & 0.04 \\
\hline \multicolumn{4}{|l|}{ Placebo+ } \\
\hline Mycophenolate & $54(34 \%)$ & $98(27 \%)$ & \\
\hline Euro-Lupus & $11(7 \%)$ & $34(9 \%)$ & \\
\hline \multicolumn{4}{|l|}{ Ocrelizumab low dose +} \\
\hline Mycophenolate & 20 (13\%) & 59 (16\%) & \\
\hline Euro-Lupus & $13(8 \%)$ & $34(9 \%)$ & \\
\hline \multicolumn{4}{|l|}{ Ocrelizumab high dose +} \\
\hline Mycophenolate & $14(9 \%)$ & $65(18 \%)$ & \\
\hline Euro-Lupus & $17(11 \%)$ & $31(9 \%)$ & \\
\hline Rituximab+ mycophenolate & $28(18 \%)$ & $44(12 \%)$ & \\
\hline $\begin{array}{l}\text { Diastolic blood pressure, } \mathrm{mm} \mathrm{Hg} \\
\text { Mean } \pm \text { SD }\end{array}$ & $83.6 \pm 14.4$ & $78.3 \pm 11.8$ & $<0.001$ \\
\hline $\begin{array}{l}\text { Systolic blood pressure, } \mathrm{mm} \mathrm{Hg} \\
\text { Mean } \pm S D\end{array}$ & $130.8 \pm 20$ & $124 \pm 16$ & $<0.001$ \\
\hline $\begin{array}{l}\text { Body mass index, } \mathrm{kg} / \mathrm{m}^{2} \\
\text { Mean } \pm \mathrm{SD}\end{array}$ & $25.7 \pm 5.8$ & $24.7 \pm 5.3$ & 0.06 \\
\hline Biopsy class & & & 0.001 \\
\hline Class III only & $10(6 \%)$ & $66(18 \%)$ & \\
\hline Class III and V & $20(13 \%)$ & $31(8.5 \%)$ & \\
\hline Class IV only & 99 (63\%) & 229 (63\%) & \\
\hline Class IV and V & $28(18 \%)$ & 39 (10.5\%) & \\
\hline Mixed with Class V & $48(30.5 \%)$ & $70(19 \%)$ & 0.004 \\
\hline $\begin{array}{l}\text { Creatinine, mg/dL } \\
\text { Median (IQR range) }\end{array}$ & $0.87(0.65-1.29)$ & $0.81(0.66-1.05)$ & 0.1 \\
\hline $\begin{array}{l}\text { Glomerular filtration rate, } \mathrm{ml} / \mathrm{min} \\
\text { Median IQR (range) }\end{array}$ & $73(51.3-107.3)$ & $91(66.6-116.5)$ & $<0.001$ \\
\hline $\begin{array}{l}\text { Urine protein/creatinine ratio } \\
\text { Mean } \pm \text { SD } g / g\end{array}$ & $6.7 \pm 2.5$ & $2.2 \pm 1.7$ & $<0.001$ \\
\hline $\begin{array}{l}\text { Albumin, } g / L \\
\text { Mean } \pm S D\end{array}$ & $2.3 \pm 0.5$ & $3.3 \pm 0.5$ & $<0.001$ \\
\hline
\end{tabular}




\begin{tabular}{llll}
\hline & $\begin{array}{l}\text { Nephrotic syndrome, N=157 } \\
(\mathbf{3 0 \% )}\end{array}$ & $\begin{array}{l}\text { Without nephrotic } \\
\text { syndrome, N=365 (70\%) }\end{array}$ & P value \\
\hline $\begin{array}{l}\text { Immunoglobulin G, g/L } \\
\text { Mean }\end{array}$ & $7.9 \pm 4.7$ & $10.8 \pm 5.2$ & $<0.001$ \\
$\begin{array}{l}\text { C3, mg/dL } \\
\text { Median (IQR range) }\end{array}$ & $59.6(47-78)$ & $65(50-87)$ & 0.02 \\
Anti-dsDNA positivity & $118(75 \%)$ & $292(80 \%)$ & 0.2 \\
\hline
\end{tabular}

substantially larger decreases in proteinuria compared with non-nephrotic subjects, greater probability of achieving a negative anti-dsDNA antibody, as well as equal probability of normalising C3. In addition, a majority of participants achieved resolution of their nephrotic syndrome.

The difference in outcomes between participants with nephrotic syndrome and those without could be due to the former having higher levels of renal disease activity at baseline as evidenced by their lower baseline eGFRs and C3 levels. Siu et $a l^{15}$ similarly found that participants with nephrotic syndrome had higher creatinine and lower C3 levels at baseline. Low albumin has been correlated with higher disease activity in both subjects with lupus nephritis and subjects with extrarenal lupus. ${ }^{34}$ Additionally, low serum albumin increases creatinine tubular secretion 35 ;6; therefore, eGFR calculations overestimate true GFR in subjects with nephrotic syndrome. It is likely this subgroup of participants had more severe renal disease than was apparent by the use of routine eGFR calculations. Furthermore, nephrotic syndrome participants had an increased proportion of mixed histology, III/V or IV $/ \mathrm{V}$, indicating more complex pathology which might respond more slowly and less completely than Class III or IV without membranous lesions.

In spite of the fact that subjects with nephrotic syndrome may have more severe or complex disease, they had a greater probability of achieving a negative anti-dsDNA antibody than those who were non-nephrotic. This could be due to the specific type of anti-dsDNA that is associated with nephrotic syndrome, as it could be of a less pathogenic variant and thus more easily treatable. ${ }^{37}$ However, this finding could also be an indication that subjects with nephrotic syndrome have modifiable disease even if this is not apparent by absolute proteinuria and creatinine thresholds.

The difference in outcomes could also be due to nephrotic syndrome affecting pharmacokinetics. Subjects with nephrotic syndrome have increased rituximab clearance, ${ }^{38} 39$ likely due to elevated levels of rituximab in their urine. ${ }^{40} 41$ This could have an impact in medication efficacy as evidenced by recent data from
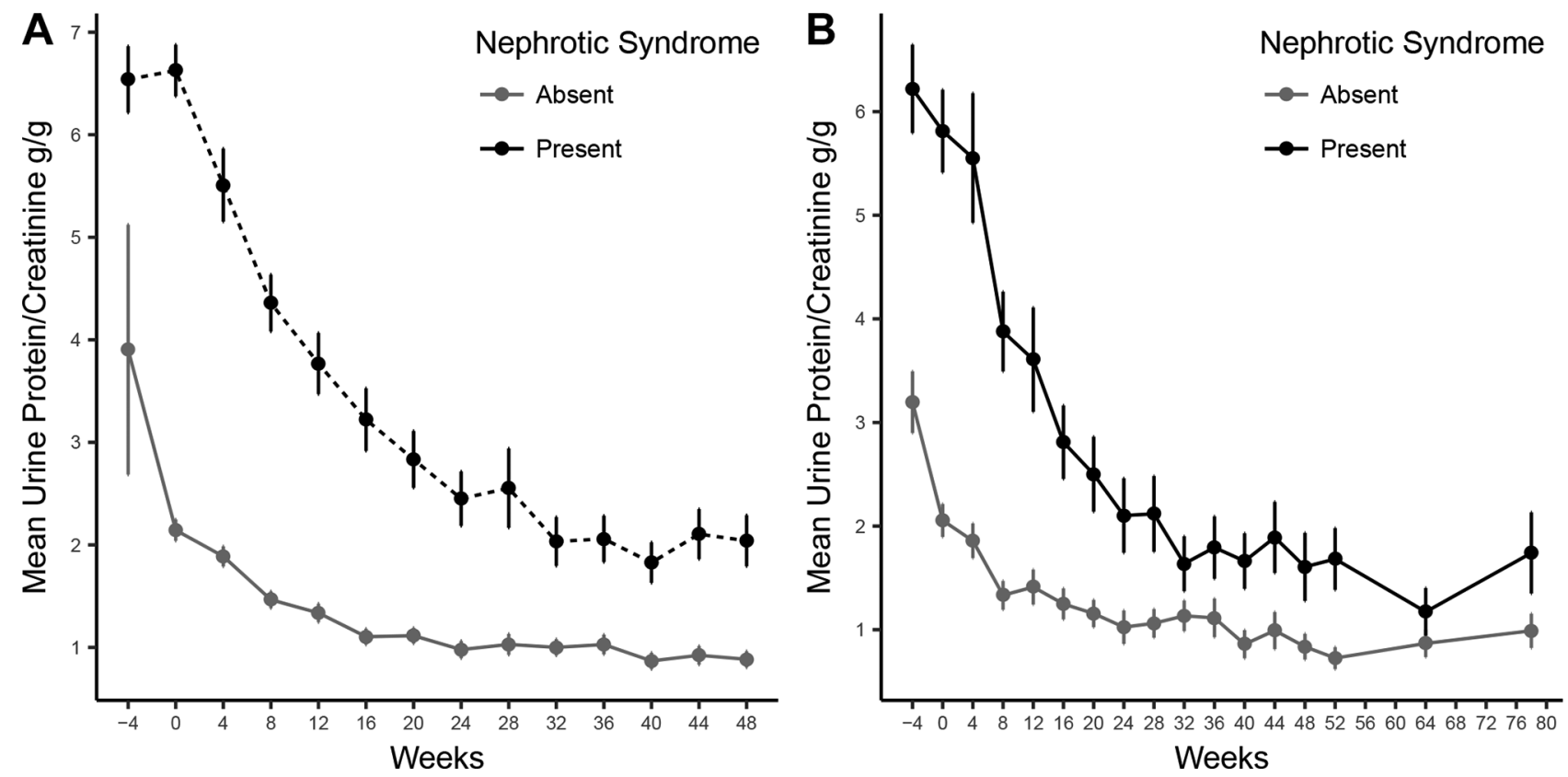

Figure 1 (A) Mean urine protein/creatinine ratio (UPCR) and SEM in participants from the combined Lupus Nephritis Assessment of Rituximab (LUNAR) and A Study to Evaluate Ocrelizumab in Patients With Nephritis due to Systemic Lupus Erythematosus trials with complete UPCR information up to week 48, comparing those with baseline nephrotic syndrome $(n=108)$ versus those without $(n=248)$. (B) Mean UPCR and SEM in participants from the LUNAR trial with complete UPCR information up to week 78, comparing those with baseline nephrotic syndrome $(n=48)$ versus those without $(n=72)$. 
A

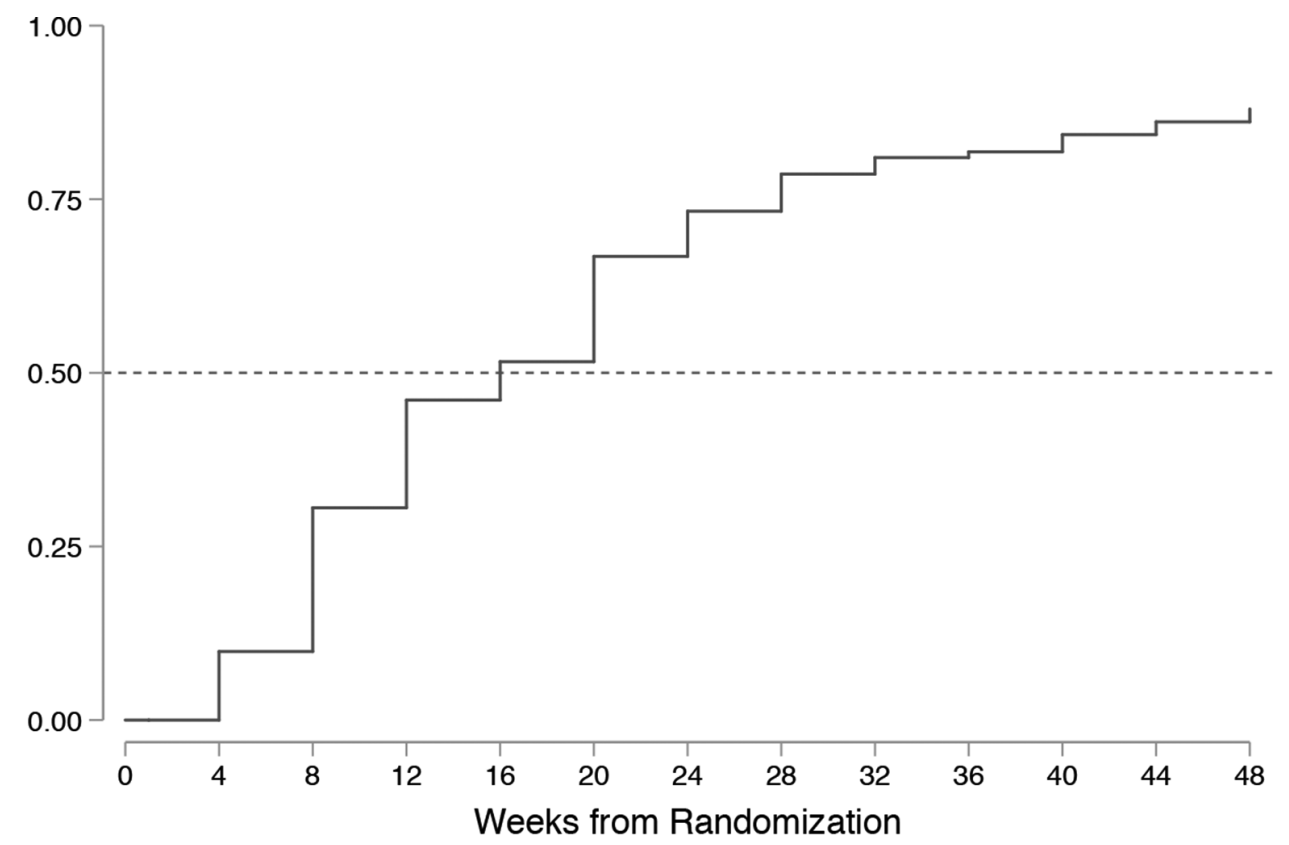

Number at risk

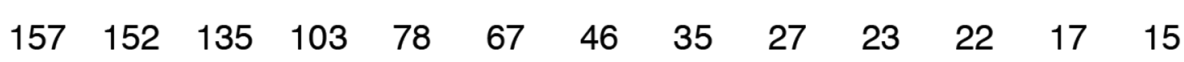

\section{B}

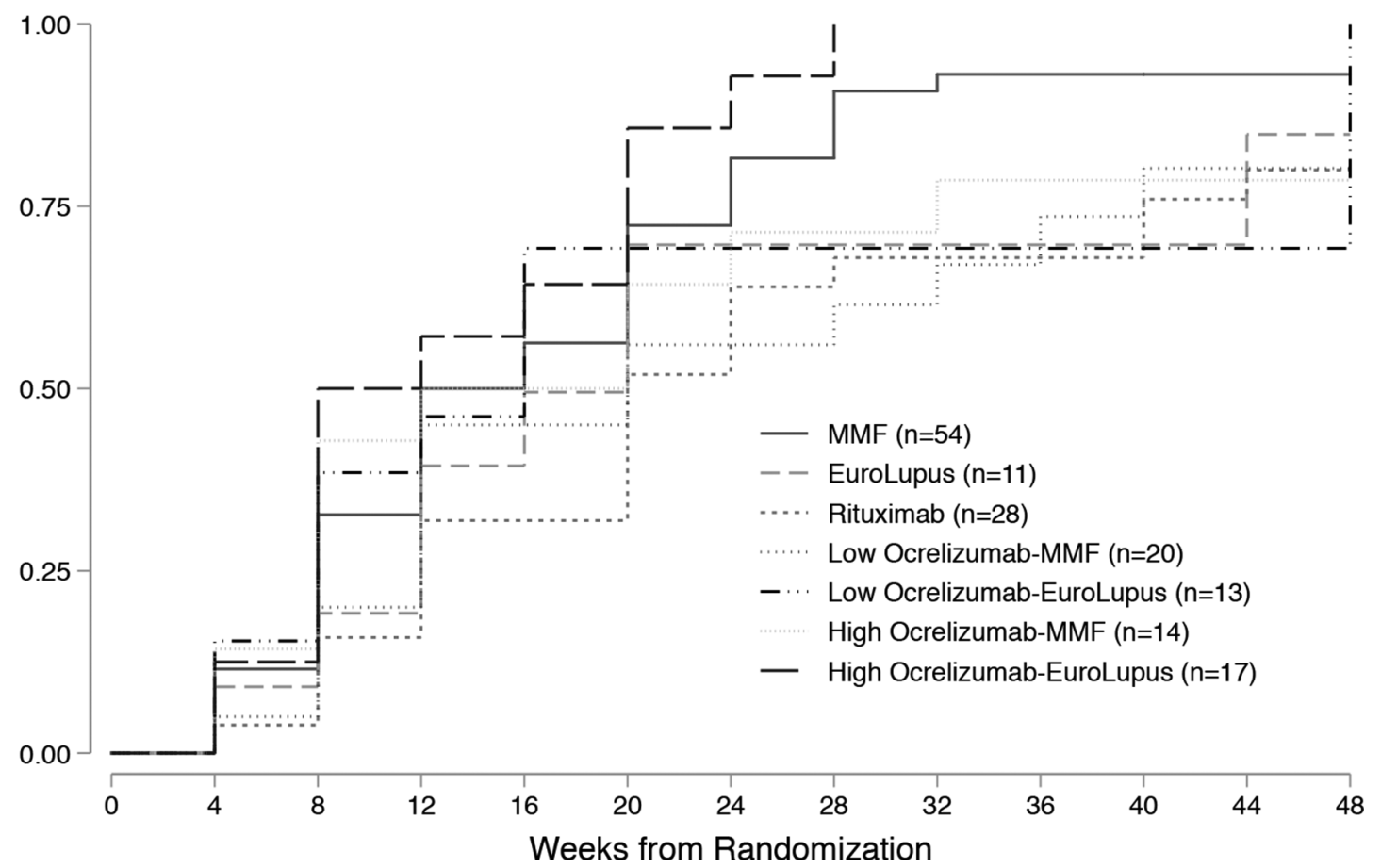

Figure 2 (A and B) Kaplan-Meier curve depicting time to resolution of nephrotic syndrome in weeks by treatment received $(n=157)$. Line depicts $50 \%$ of participants have achieved resolution of nephrotic syndrome.

the LUNAR trial which has shown that subjects with nephrotic syndrome are less likely to achieve adequate B cell depletion after rituximab administration. ${ }^{42}$ Similar studies in subjects with nephrotic syndrome have not yet been performed for ocrelizumab. Notably, subjects with nephrotic syndrome were not treated with significantly higher average daily steroid doses or higher average daily MMF doses. Because MMF is highly bound to albumin, hypoalbuminaemia increases the concentration of the pharmacologically active metabolite. ${ }^{43}$ As with MMF, the pharmacologically active unbound fraction of prednisone is also increased in the setting of hypoalbuminaemia. ${ }^{44}$ These findings underscore the importance of taking nephrotic syndrome in consideration when evaluating new medications for lupus nephritis. Nephrotic syndrome is common in lupus nephritis, and altered pharmacokinetics could ultimately affect the efficacy of therapeutic interventions. 
Table 2 Characteristics of participants with baseline nephrotic syndrome from the combined Lupus Nephritis Assessment of Rituximab and A Study to Evaluate Ocrelizumab in Patients With Nephritis due to Systemic Lupus Erythematosus trials comparing those who achieved renal response versus those who did not

\begin{tabular}{|c|c|c|c|}
\hline & $\begin{array}{l}\text { Renal response, } \\
\mathrm{N}=28(26 \%)\end{array}$ & $\begin{array}{l}\text { No response, } N=80 \\
(74 \%)\end{array}$ & $P$ value \\
\hline $\begin{array}{l}\text { Baseline UPCR, } g / g \\
\text { Mean } \pm \text { SD }\end{array}$ & $5.6 \pm 1.9$ & $6.9 \pm 2.6$ & 0.02 \\
\hline $\begin{array}{l}\text { Baseline albumin, } g / L \\
\text { Mean } \pm S D\end{array}$ & $2.3 \pm 0.3$ & $2.2 \pm 0.5$ & 0.1 \\
\hline $\begin{array}{l}\text { Change in UPCR at } 24 \text { weeks, } g / g \\
\text { Mean } \pm \text { SD }\end{array}$ & $-4.9 \pm 2.2$ & $-3.8 \pm 3.4$ & 0.1 \\
\hline $\begin{array}{l}\text { Change in albumin at } 24 \text { weeks, } g / L \\
\text { Mean } \pm \text { SD }\end{array}$ & $1.1 \pm 0.5$ & $1 \pm 0.5$ & 0.5 \\
\hline $\begin{array}{l}\text { Change in UPCR at } 48 \text { weeks, } g / g \\
\text { Mean } \pm \text { SD }\end{array}$ & $-5.5 \pm 2$ & $-4.3 \pm 3.9$ & 0.1 \\
\hline $\begin{array}{l}\text { Change in albumin at } 48 \text { weeks, } g / L \\
\text { Mean } \pm \text { SD }\end{array}$ & $1.6 \pm 0.6$ & $1.3 \pm 0.7$ & 0.06 \\
\hline Normalised C3, $\geq 90 \mathrm{mg} / \mathrm{dL}$ & $18(64 \%)$ & $59(74 \%)$ & 0.3 \\
\hline Treated with anti-CD20 & $18(64 \%)$ & $48(60 \%)$ & 0.6 \\
\hline Mixed with class 5 & $9(32 \%)$ & $28(35 \%)$ & 0.7 \\
\hline $\begin{array}{l}\text { Change in systolic blood pressure, } \mathrm{mm} \mathrm{Hg} \\
\text { Mean } \pm \text { SD }\end{array}$ & $-24 \pm 21$ & $-13 \pm 21$ & 0.02 \\
\hline $\begin{array}{l}\text { Change in diastolic blood pressure, } \mathrm{mm} \mathrm{Hg} \\
\text { Mean } \pm \text { SD }\end{array}$ & $-13 \pm 18$ & $-6 \pm 16$ & 0.04 \\
\hline $\begin{array}{l}\text { Change in glomerular filtration rate, } \mathrm{mL} / \mathrm{min} \\
\text { Mean } \pm \mathrm{SD}\end{array}$ & $28 \pm 24$ & $14 \pm 40$ & 0.08 \\
\hline $\begin{array}{l}\text { Change in creatinine, } \mathrm{mg} / \mathrm{dL} \\
\text { Mean } \pm \mathrm{SD}\end{array}$ & $-0.15 \pm 0.2$ & $-0.09 \pm 0.5$ & 0.5 \\
\hline
\end{tabular}

UPCR, urine protein/creatinine ratio.

Participants with nephrotic syndrome that achieved renal response had lower baseline UPCR compared with non-responders. However, similar to prior research ${ }^{28}$ overall decrease in proteinuria between groups was not significantly different, suggesting that a more prolonged observation time might have allowed more nephrotic participants to reach the $0.5 \mathrm{~g} / \mathrm{g}$ proteinuria threshold. Subjects with nephrotic syndrome from LUNAR followed up to week 78 had their proteinuria nadir at week 64, whereas non-nephrotic participants had their proteinuria nadir at week 52. This finding provides support for the hypothesis that longer trials may better assess efficacy of novel therapeutic approaches in subjects with nephrotic syndrome. All nephrotic responders had greater than $50 \%$ reduction in proteinuria at week 24 , supporting the hypothesis that reduction in proteinuria in the first 6 months of treatment could be a predictor of long-term renal outcomes for nephrotic syndrome participants.

Despite the fact that the majority of participants with nephrotic syndrome did not achieve the endpoint of the trials, we do not advocate that they be excluded from future lupus nephritis trials. This would greatly limit our understanding of how these participants differ from those who are non-nephrotic as well as what therapies would work best for them. Instead, it may be prudent to prespecify baseline nephrotic syndrome as a subgroup for analysis and perhaps even as a stratification variable to ensure balance in the distribution of patients with nephrotic syndrome across treatment groups. In this way, rates of renal response in those with nephrotic syndrome as well as time to resolution of nephrotic syndrome could be directly compared across treatment arms. Additionally, better short-term predictors of long-term outcomes can be found and validated as endpoints, or trials that include participants with nephrotic syndrome can be designed to assess endpoints at 1.5 or 2 years.

Limitations of this study include that this is a post hoc analysis of two randomised controlled trials. Our exposure of interest and our outcome are both based on proteinuria. Ideally, an outcome that is not based on proteinuria such as repeat renal biopsy would be used; however, repeat biopsies can be difficult to obtain in clinical trials and were not required for participation in LUNAR or BELONG. The duration of follow-up was limited to 48 weeks. 


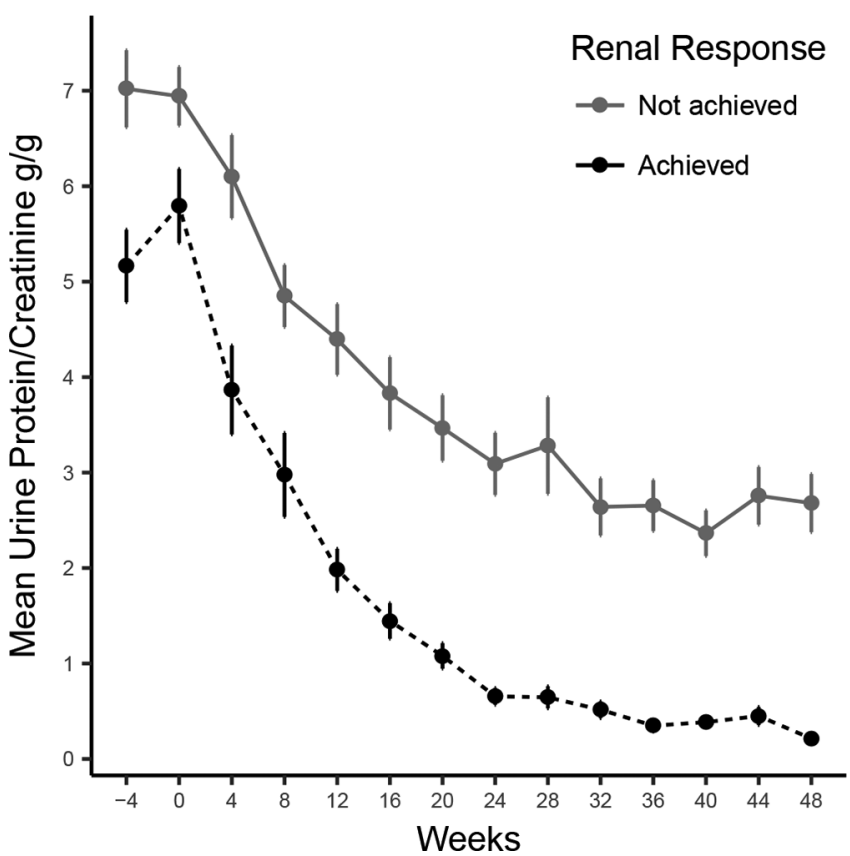

Figure 3 Mean urine protein/creatinine ratio (UPCR) and SEM of participants from the combined Lupus Nephritis Assessment of Rituximab and A Study to Evaluate Ocrelizumab in Patients With Nephritis due to Systemic Lupus Erythematosus trials with baseline nephrotic syndrome and complete UPCR information up to week 48, comparing responders $(n=28)$ versus non-responders $(n=80)$.

In summary, subjects with baseline nephrotic syndrome had significantly lower likelihood of achieving renal response, as measured by creatinine and proteinuria, at 1 year. Nonetheless, they demonstrated clinically important improvements during the trials. In conclusion, longitudinal studies are necessary to better understand the overall prognosis of this subgroup of participants and to evaluate more adequate endpoints for use in future lupus nephritis trials.

Acknowledgements LUNAR and BELONG trials were sponsored by Genentech/ Roche.

Contributors LMGM, MDC, JG, and P.Brunetta, conceived the present idea. LMGM and MDC. analyzed the data. All authors participated in the interpretation of data, revised the manuscript critically and approved of the final version.

Funding The authors have not declared a specific grant for this research from any funding agency in the public, commercial or not-for-profit sectors.

Competing interests MDC, JG, TRK and PB are employees of Roche/Genentech. LMGM, PB, MD'E, DJ and BR have no disclosures.

Patient consent for publication Obtained.

Ethics approval The LUNAR and BELONG study protocols were approved by institutional review boards and ethics committees and adhered to the Declaration of Helsinki. Participants provided written informed consent.

Provenance and peer review Not commissioned; externally peer reviewed. Data sharing statement Qualified researchers may request access to individual patient level data through the clinical study data request platform (www.clinical studydatarequest.com). Further details on Roche's criteria for eligible studies are available here (https://clinicalstudydatarequest.com/Study-Sponsors/ Study-Sponsors-Roche.aspx). For further details on Roche's Global Policy on the Sharing of Clinical Information and how to request access to related clinical study documents, see here (https://www.roche.com/research_and_development/who we_are_how_we_work/clinical_trials/our_commitment_to_data_sharing.htm)".

Open access This is an open access article distributed in accordance with the Creative Commons Attribution Non Commercial (CC BY-NC 4.0) license, which permits others to distribute, remix, adapt, build upon this work non-commercially, and license their derivative works on different terms, provided the original work is properly cited, appropriate credit is given, any changes made indicated, and the use is non-commercial. See: http://creativecommons.org/licenses/by-nc/4.0/.

\section{REFERENCES}

1. Macé C, Chugh SS. Nephrotic syndrome: components, connections, and angiopoietin-like 4-related therapeutics. J Am Soc Nephrol 2014;25:2393-8.

2. Kerlin BA, Ayoob R, Smoyer WE. Epidemiology and pathophysiology of nephrotic syndrome-associated thromboembolic disease. Clin J Am Soc Nephrol 2012;7:513-20.

3. Gigante A, Barbano B, Sardo L, et al. Hypercoagulability and nephrotic syndrome. Curr Vasc Pharmacol 2014;12:512-7.

4. Orth SR, Ritz E. The nephrotic syndrome. N Engl J Med 1998;338:1202-11.

5. Moroni G, Ventura D, Riva P, et al. Antiphospholipid antibodies are associated with an increased risk for chronic renal insufficiency in patients with lupus nephritis. Am J Kidney Dis 2004;43:28-36.

6. Moroni G, Quaglini S, Gallelli B, et al. Progressive improvement of patient and renal survival and reduction of morbidity over time in patients with lupus nephritis (Ln) followed for 20 years. Lupus 2013;22:810-8.

7. Yokoyama $\mathrm{H}$, Okuyama $\mathrm{H}$, Yamaya $\mathrm{H}$. Clinicopathological insights into lupus glomerulonephritis in Japanese and Asians. Clin Exp Nephrol 2011;15:321-30.

8. Yokoyama H, Wada T, Hara A, et al. The outcome and a new ISN/ RPS 2003 classification of lupus nephritis in Japanese. Kidney Int 2004;66:2382-8.

9. Pinto Peñaranda LF, Castro Mercado IL, Duque Caballero V, et al. Predictive risk factors for failure to induction therapy of lupus nephritis in a cohort of Colombian patients. Reumatología Clínica 2014;10:147-51.

10. Qin DD, Song D, Huang J, et al. Plasma-soluble urokinase-type plasminogen activator receptor levels are associated with clinical and pathological activities in lupus nephritis: a large cohort study from China. Lupus 2015;24:546-57.

11. Pang Y, Tan Y, Li Y, et al. Pentraxin 3 is closely associated with tubulointerstitial injury in lupus nephritis: a large multicenter crosssectional study. Medicine 2016;95:e2520.

12. Mok CC, To CH, Yu KL, et al. Combined low-dose mycophenolate mofetil and tacrolimus for lupus nephritis with suboptimal response to standard therapy: a 12-month prospective study. Lupus 2013;22:1135-41.

13. Mok CC, Ying KY, Yim CW, et al. Tacrolimus versus mycophenolate mofetil for induction therapy of lupus nephritis: a randomised controlled trial and long-term follow-up. Ann Rheum Dis 2016;75:30-6.

14. Guo Q, Lu X, Miao L, et al. Analysis of clinical manifestations and pathology of lupus nephritis: a retrospective review of 82 cases. Clin Rheumatol 2010;29:1175-80.

15. Sui M, Jia X, Yu C, et al. Clinical immunology relationship between hypoalbuminemia, hyperlipidemia and renal severity in patients with lupus nephritis: a prospective study. Cejoi 2014;2:243-52.

16. Houssiau FA, Vasconcelos C, D'Cruz D, et al. The 10-year follow-up data of the Euro-Lupus nephritis trial comparing low-dose and highdose intravenous cyclophosphamide. Ann Rheum Dis 2010;69:61-4.

17. Moroni G, Ponticelli C. The multifaceted aspects of refractory lupus nephritis. Expert Rev Clin Immunol 2015;11:281-8.

18. Moroni G, Quaglini S, Gravellone L, et al. Membranous nephropathy in systemic lupus erythematosus: long-term outcome and prognostic factors of 103 patients. Semin Arthritis Rheum 2012;41:642-51.

19. Hu W, Chen Y, Wang S, et al. Clinical-Morphological features and outcomes of lupus podocytopathy. Clin J Am Soc Nephrol 2016;11:585-92.

20. Wang Y, Yu F, Song D, et al. Podocyte involvement in lupus nephritis based on the 2003 ISN/RPS system: a large cohort study from a single centre. Rheumatology 2014;53:1235-44.

21. Kraft SW, Schwartz MM, Korbet SM, et al. Glomerular podocytopathy in patients with systemic lupus erythematosus. J Am Soc Nephrol 2005;16:175-9.

22. Desai N, Cimbaluk D, Lewis EJ, et al. Proteinuria in membranous lupus nephritis: the pathology is in the podocyte. Lupus 2013;22:461-8.

23. Han TS, Schwartz MM, Lewis EJ. Association of glomerular podocytopathy and nephrotic proteinuria in mesangial lupus nephritis. Lupus 2006;15:71-5.

24. Lech M, Anders HJ. The pathogenesis of lupus nephritis. J Am Soc Nephrol 2013;24:1357-66. 
25. Trivedi S, Zeier M, Reiser J. Role of podocytes in lupus nephritis. Nephrology Dialysis Transplantation 2009;24:3607-12.

26. Weening JJ, D'Agati VD, Schwartz MM, et al. The classification of glomerulonephritis in systemic lupus erythematosus revisited. J Am Soc Nephrol 2004;15:241-50.

27. Touma Z, Urowitz MB, Ibañez D, et al. Time to recovery from proteinuria in patients with lupus nephritis receiving standard treatment. J Rheumatol 2014;41:688-97.

28. Korbet SM, Lewis EJ, Collaborative Study Group. Complete remission in severe lupus nephritis: assessing the rate of loss in proteinuria. Nephrol Dial Transplant 2012;27:2813-9.

29. Houssiau FA, Vasconcelos C, D'Cruz D, et al. Early response to immunosuppressive therapy predicts good renal outcome in lupus nephritis: lessons from long-term followup of patients in the eurolupus nephritis trial. Arthritis Rheum 2004;50:3934-40.

30. Rovin BH, Furie R, Latinis $\mathrm{K}$, et al. Efficacy and safety of rituximab in patients with active proliferative lupus nephritis: the Lupus nephritis assessment with rituximab study. Arthritis Rheum 2012;64:1215-26.

31. Mysler EF, Spindler AJ, Guzman R, et al. Efficacy and safety of ocrelizumab in active proliferative lupus nephritis: results from a randomized, double-blind, phase III study. Arthritis Rheum 2013;65:2368-79.

32. Houssiau FA, Vasconcelos C, D'Cruz D, et al. Immunosuppressive therapy in lupus nephritis: the Euro-Lupus nephritis trial, a randomized trial of low-dose versus high-dose intravenous cyclophosphamide. Arthritis Rheum 2002;46:2121-31.

33. Díaz-Lagares $C$, Croca S, Sangle S, et al. Efficacy of rituximab in 164 patients with biopsy-proven lupus nephritis: pooled data from European cohorts. Autoimmun Rev 2012;11:357-64.

34. Yip J, Aghdassi E, Su J, et al. Serum albumin as a marker for disease activity in patients with systemic lupus erythematosus. J Rheumatol 2010;37:1667-72.
35. Branten AJW, Vervoort G, Wetzels JFM. Serum creatinine is a poor marker of GFR in nephrotic syndrome. Nephrology Dialysis Transplantation 2005;20:707-11.

36. Horio M, Imai E, Yasuda Y, et al. Lower serum albumin level is associated with higher fractional excretion of creatinine. Clin Exp Nephrol 2014;18:469-74.

37. Yung S, Chan TM. Anti-dsDNA antibodies and resident renal cells - Their putative roles in pathogenesis of renal lesions in lupus nephritis. Clin Immunol 2017:185:40-50.

38. Fervenza FC, Abraham RS, Erickson SB, et al. Rituximab therapy in idiopathic membranous nephropathy: a 2-year study. Clin J Am Soc Nephrol 2010;5:2188-98.

39. Fervenza FC, Cosio FG, Erickson SB, et al. Rituximab treatment of idiopathic membranous nephropathy. Kidney Int 2008;73:117-25.

40. Stahl K, Duong M, Schwarz A, et al. Kinetics of rituximab excretion into urine and peritoneal fluid in two patients with nephrotic syndrome. Case Rep Nephrol 2017;2017:1-8.

41. Jacobs R, Langer-Jacobus T, Duong M, et al. Detection and quantification of rituximab in the human urine. $\mathrm{J}$ Immunol Methods 2017;451:118-21.

42. Gomez Mendez LM, Cascino MD, Garg J, et al. Peripheral blood $B$ cell depletion after rituximab and complete response in lupus nephritis. Clin J Am Soc Nephrol 2018;13:CJN.01070118-9.

43. Atcheson BA, Taylor PJ, Kirkpatrick CM, et al. Free mycophenolic acid should be monitored in renal transplant recipients with hypoalbuminemia. Ther Drug Monit 2004;26:284-6.

44. Shibasaki H, Nakayama H, Furuta T, et al. Simultaneous determination of prednisolone, prednisone, cortisol, and cortisone in plasma by GC-MS: estimating unbound prednisolone concentration in patients with nephrotic syndrome during oral prednisolone therapy. J Chromatogr B 2008;870:164-9. 